\title{
Indonesian authors' stances in citing English research article introductions literature in sciences
}

\author{
1Suci Miasari, ${ }^{2}$ Safnil Arsyad and ${ }^{3}$ Arono* \\ ${ }^{123}$ English Education Postgraduate Program \\ University of Bengkulu, Bengkulu Indonesia \\ ${ }^{*}$ Corresponding author \\ Email: safnil@unib.ac.id
}

\begin{abstract}
Authorial stance is an important aspect in academic texts in academic texts such as research articles (RAs); that is to show the attitude of authors toward the information cited in a reference in order to establish an argument. The objective of this research was to investigate the authorial stances in English RA introductions written by Indonesia authors in the field of sciences (i.e. Biology, Physic and Chemistry). This research employed a descriptive qualitative method. Thirty English research article introductions were included in the corpus in this study. The results show that two authorial stances: neutral and positive stances are found in the texts but no critical stance is used in the corpus of this research. Also, four types of authorial stance (i.e., hedges, booster, attitudinal markers, and self- mention) are used in the RA introductions and the devices in each type of authorial stance are nouns, verbs, adverbs, adjectives and modals. Self-mentions found in this research are subjective pronoun, common noun and possessive adjectives. It can be concluded that Indonesian authors in the field of sciences already use similar types of authorial stances in their English RA introductions to those of international authors writing in English.
\end{abstract}

Keywords: Authorial stances, English research article introductions, Indonesian authors, science journals

$\begin{array}{llll}\text { Received: } & \text { Revised: } & \text { Accepted: } & \text { Published: } \\ \text { 01 December 2017 } & \text { 27 July 2018 } & \text { 30 August 2018 } & \text { 31 August 2018 }\end{array}$

\section{INTRODUCTION}

At college stage, students cannot be separated from academic writing activity which is a way to express their ideas, opinions, thoughts and feelings. For example, all university students are required to write a scientific essay which is useful to develop the knowledge they already obtained and also as a requirement for their graduation. Similarly, lecturers and professional researchers are also required to write scientific articles in which they manage, organise, present and distribute thoughts, ideas, facts, and data, so that they become useful information for anyone who need them. Writing a scientific article can help success in completion of their studies at university and writing 
skill of scientific articles are also useful for other scientific activities, such as seminars, training, workshops, and the like (Supriyadi, 2013). It means that writing a scientific article as the main activity has several important roles to support students in running their academic activities and also as component which will contribute to knowledge development.

After writing a scientific article, writers need to publish it in a research journal. According to the Directorate general of Higher Education of Ministry of Education and Culture (2012), the amount of journal articles of universities in Indonesia is still below that of Malaysia. Thus, after writing a scientific article, the writer should publish it in a journal in order to boost the international publication of Indonesian authors. Similarly, according to Supriyadi (2013), a research is an activity that requires energy, time, and very expensive. Publishing research finding is very useful for the development of science. In other words, the research reports can not only be stored in the library of a university but it must be shared to others who might need it. It is also supported by Arsyad (2016) when he says that there is one more step that is expected to be conducted by researchers after completing their research; that is to publish the results in a journal. Thus, the research results can be useful for many people who want to develop, enhance and apply the knowledge.

There are probably many obstacles in writing a good and understandable text that should be delivered well. Besides, it is considered being difficult to succeed in publishing research article, especially to publish it in an international journal. According to Arsyad (2016), the main reason of the difficulties in publishing an article in international journals is the poor ability of the writer in writing in English. Hasan (2009) explains that scientific article is a scientific publication that contains information about the results of the activities of science; the publication is written in the form of scientific articles both derived from the results of research and developed from concept or theory. It means that, beside the need to practice writing an article, a researcher is supposed to follow a guideline to help them $\mathrm{n}$ write in order to know the criteria of writing in English that will be acceptable in journal, especially in international journals.

One problem that is often experienced by new writers especially college students is that they find it hard to find specific guidelines in writing scientific article, but they usually find a guidebook to write scientific article in general. Getkham (2016) suggests that, writers have to be able to present the research findings, make comments about the empirical evidence and produce appropriate critical comments, in order to persuade the readers to accept their claims. While, according to Chang (2010), authors especially when writing in a second or foreign language, face several challenges, such as difficulties in giving interpretation, reasoning, and argument in order to provide a convincing argument. Similarly, Waseso (2016) suggests that negative transfer from the first language competence can also be a problem if it is different from that of in the foreign language.

In recent years, there has been concern about how writers can effectively and appropriately use language in order to make their texts more interactional and attract readers to read. Author's stance, for example, has been found to be an important aspect in order to make the message can be delivered well. 
Conrad and Biber (cited in Cakir, 2016) state that stance is an attitude which can reflect the writers' attitude towards an issue, event or person; thus authorial stance can present writers' viewpoint on the components of their work they introduce. Thus, in developing convincing arguments writers should position themselves appropriately and therefore, writers need to use appropriate attitude in their writing and the writers to be effective and appropriate.

Stance can be in the form of self-reference words, modal verbs, attitudinal markers and many others; each of them has its function. For example, the use of self-reference such as the researcher, the author, $I$, we etc. is to show their contribution in the research findings (Hyland, 2005). Modal verbs such as "will", "would" can be used in presenting the research, such as introducing the research questions and hypotheses of the study (Pho, 2013) and attitudinal markers such as "important" and "neglected" to express authors' viewpoints and evaluations in expressing the writers' positive or negative opinion, certainty or likelihood, desirability or goodness, obvious or expectedness, and importance or relevance (Thompson and Hunston cited in Pho, 2013). It can be seen that, stance as the writer's way to show their expression of attitude, viewpoint, and judgement, so the appropriate stance is important to use in order to deliver the cited information and knowledge well. Besides that, the good ways of writers in expressing their stance in writing can also help them persuade readers to read (Hunston cited in Pho, 2013).

The importance of authorial stance has been suggested by researchers or authors in the literature. They found that, most work consists of different stances, whether they are from national journal or international journal; the writers express their feeling, viewpoint and judgment in different way. It means that there are variations of stance used by the writers in writing journal articles. Thus, stance is used by writer to express their attitude and this is important in helping writers to use effective and acceptable language in their texts.

Introduction section of an article, according to Soule et al. (2007), is aimed to communicate to readers the research area and the author's stance with respect to it. In addition, Getkham (2016) says that writers need to use appropriate critical comments, judgements, and present their study. It means that the ability to position ourselves and persuade readers to accept our claims. So, making our writing more interactional is a competency that should be owned by the writers; therefore, researchers need to find out the authorial stance used in journal article Introduction.

There are several studies related to authorial stance that can be found in the literature. Getkham (2016), for example, investigated authorial stance in Thai students' doctoral dissertation. He investigated the types of authorial stances such as hedging, boosters, attitudinal markers and self-mentions as proposed by Hyland (2005) in the students' texts. This study used 36 introduction and discussion sections taken from different universities in the US during the periods of 2008-2013. The results showed that, authorial stances used in the students' dissertation were hedges and boosters. According to Hyland, the use of hedging and boosting devices is aimed to protect authors from any critics and show a degree of confidence while attitudinal markers are used to state that general research area are important, 
interesting, and problematic; while, self-mentions are not often used by the student authors. This is, according to Hyland, because the traditional nature of research writing is objective, impersonal, and unbiased.

Another research was conducted by Cakir (2016) entitled "Native and NonNative Writers' Use of Stance Adverbs in English Research Article Abstracts". This research investigated RA abstracts in soft sciences (Psychology, linguistics, sociology) and hard sciences (Biology, Physic, Chemistry). The corpus of this study consisted of 240 English abstracts written by English native speakers and Turkish speakers taken from the publication periods of 2005-2009 focusing on the stance adverbs as one of authorial stance expression. This study found that significant differences in the total number of stance adverbs used in the abstracts; native English writers used more stance adverbs in their abstracts than Turkish writers. Differences were also found of stance adverbs in hard sciences and academic writers in the soft sciences used more stance adverbs in their abstracts.

Studies have found that stance as communicative strategies are useful to persuade and attract readers to read their texts. Pho (2013) explains that stance is the way writers present themselves to readers and the way their judgments, opinions, and commitments are conveyed. In addition, Adnan (2016) explains that the importance of attitude is to understand to what extent the citing authors involve the cited information in presenting knowledge, whether they accept it or evaluate it. Although stance has been investigated in written texts in the field of Sociology, Psychology, linguistics, Physic, Biology, Chemistry but, to the knowledge on these writers, no such study has been conducted on English research articles in sciences, such as Biology, Physic and Chemistry written by Indonesian authors. This is the rationale for this study; that is to investigate how authorial stances are used by Indonesian speakers when writing RA introductions in English in the field of sciences. The research questions for this study are the followings:

1. How are the authorial stances found in English research article Introductions written by Indonesian authors in the field of Sciences?

2. What types of authorial stances are found in English research article Introductions written by Indonesian authors in the field of Sciences? And

3. What devices are found in each of authorial stance types of English research article Introductions written by Indonesian authors in the field of Sciences?

\section{METHOD}

\section{The Corpus of the Study}

This study was conducted in both descriptive quantitative and qualitative research method. This research used thirty English research articles in sciences (i.e. Biology, Physic and Chemistry) and only focused on introduction sections as the corpus of this study. The articles were randomly taken from online national accredited journals in sciences published from 2013 to 2017. The journals have been selected based on the accreditation status as shown in the following table. 
Table 1. The Corpus of this Study

\begin{tabular}{|c|c|c|c|c|c|}
\hline \multirow[t]{2}{*}{ No. } & \multirow[t]{2}{*}{ Journal } & \multirow[t]{2}{*}{$\begin{array}{l}\text { Accre- } \\
\text { ditation }\end{array}$} & \multicolumn{3}{|c|}{$\begin{array}{l}\text { The amount of journal articles } \\
\text { (in period 2013-2017) }\end{array}$} \\
\hline & & & Biology & Physic & Chemistry \\
\hline 1. & $\begin{array}{l}\text { Makara Journal of Science } \\
\text { (Universitas Indonesia) }\end{array}$ & $\mathrm{B}$ & 3 & 5 & 2 \\
\hline 2. & $\begin{array}{l}\text { Journal of Mathematical and } \\
\text { Fundamental Sciences (Institut } \\
\text { Teknologi Bandung) }\end{array}$ & B & 2 & 5 & 2 \\
\hline 3. & $\begin{array}{l}\text { Journal of Tropical Life Science } \\
\text { (Universitas Brawijaya) }\end{array}$ & $\mathrm{B}$ & 2 & - & 2 \\
\hline 4. & $\begin{array}{l}\text { Indonesian Journal of } \\
\text { Chemistry (Universitas Gajah } \\
\text { Mada) }\end{array}$ & $\mathrm{B}$ & & - & 4 \\
\hline 5. & $\begin{array}{l}\text { HAYATI (Istitut Pertanian } \\
\text { Bogor) }\end{array}$ & $\mathrm{B}$ & 3 & - & - \\
\hline \multicolumn{3}{|c|}{ The amounts of Journal Articles } & 10 & 10 & 10 \\
\hline
\end{tabular}

The instrument in this research was a check list of classification of authorial stances; it was designed based on the model suggested of Adnan (2016) and Hyland (2005) about authorial stances. There were three authorial stances proposed by Adnan: positive, negative and critical and there are four types of authorial stance suggested by Hyland: Hedges, Booster, Attitudinal markers and Self-mention while the devices in each types of authorial stance, according to Hyland, are adjective, adverb, noun verb and modal.

\section{Data Analysis Procedures}

The data were analysed manually by marking the stances (neutral, positive and critical in citation), types of stances (hedges, booster, attitudinal markers and self-mention), and devices in each types of stance (adjective, adverb, noun verb and modal). First, the introduction sections of the articles in the corpus of this study were read to get a thorough understanding on the content of the texts. Second, the texts were read again to identify the stances used in the texts. Third, in order to ensure that all authorial stances have been identified correctly, the analysis results were re-checked manually. Finally, the frequency of authorial stances, the types and the devises were calculated. In order to get a valid data, Waber (cited in Stemler, 2001) notes that it is important that the classification procedure be reliable in the sense of being consistent: different people may code the same text in the same way or differently. Therefore, an inter-rater reliability was conducted; two co-raters double-checked the data analysis results. They were alumni of a postgraduate program on English education. Following Arsyad (2000), for the first time coraters were trained how to identify the authorial stances using the designed research instrument; in this case they were trained on what authorial stance was and shown how them how to identify those stances, types of authorial stance and devices of each types of authorial stance. Finally, they were asked to label and code the entire authorial stances found in the 30 English research article introductions. The disagreement between researchers and co-raters in the identification of the authorial stances was discussed in order to arrive at an agreement. The results showed a high agreement with value of Kappa 
above 90; it was based on Cohen's Kappa interpretation as suggested by McHugh (2012).

\section{RESULTS AND DISCUSSION}

\section{The authorial stance found in English research article Introductions written by Indonesian authors in the field of Sciences}

The three authorial stances as suggested by Adnan (2016) namely: neutral, positive and critical are found in the data of this study. The following table (table 2) displays the data analysis results.

Table 2. Authorial Stances in RA Introductions

\begin{tabular}{clccccc}
\hline \multirow{2}{*}{ No. } & Science Fields & \multicolumn{3}{c}{ Authorial Stance } & Total & Percentage \\
\cline { 3 - 6 } & & Neutral & Positive & Critical & & \\
\hline 1. & Biology & 32 & 3 & 0 & 35 & 34.7 \\
\hline 2. & Physic & 34 & 2 & 0 & 36 & 35.6 \\
\hline 3. & Chemistry & 25 & 5 & 0 & 30 & 29.7 \\
\hline Total & 91 & 10 & 0 & 101 & 100 \\
\hline
\end{tabular}

It can be seen in Table 2 that, there are only two authorial stance found in this research: neutral and critical. The total frequency of authorial stance is 101; neutral stance was the highest frequency with total frequency of 91 (32 in Biology, 34 in Physic and 25 in Chemistry). It is different from positive and critical stances. There are only 10 positive stances found in this research $(3$ in biology, 2 in Physic and 5 in Chemistry). It is found that there are no critical stances in Biology, Physic and Chemistry. The following examples give information about the finding.

1. The availability of PSB in soil may elevate the phosphate uptake by the plant and improve the yield of the crop [5]. (Bio, 1)

2. In Flora of Java, Backer \& Bakhuizen van den brink, Jr. [12] indicated that there were 17 named of Musa species, but some of them are not valid, so revision is needed. (Bio-10)

3. The utilization of three types of LEDs that each emit a basic colour, i.e. blue, green, and red, can produce secondary and tertiary colours, covering almost all colours in everyday life [1,2]. (Phy-2)

4. Recently, it has been shown that the variability of the intra-seasonal winds over the equatorial Indian Ocean is modulated by the Indian Ocean Dipole (IOD) on inter-annual timescales [6,7]. (Phy-5)

5. Some of these phenolic compounds "showed" significant anti-microbal $[4], \ldots($ Chem-8)

6. Several raw materials can be used for biodiesel production such as sunflower oil, crude palm oil (CPO) and etc. [3-4]. (Chem-9)

As can be seen in example 1 , the authors only put the information without stating their stance, whether they agree or disagree with it. While, in example 2 , the word "indicated" show a positive stance toward the citing information, because it seems like acceptable information to support their written. Example 3 shows that the authors put neutral stance toward the citing information, 
because none information can be taken about author stance; the authors only give information about utilization of LED. It is also found in example 4 that the word "shown" indicates the positive stance about the information; because they are probably want to give information in order to support their written. Similarly, the word 'showed' in example 5 shows that authors have positive stance about the information. Besides, example 6 indicates that the authors have neutral stance toward the information; they did not take sides. It can be concluded that from three stances suggested by Adnan (2016), there are only two stances in RA introduction written by Indonesian authors in the field of sciences, such as neutral and positive stance

\section{Types of authorial stance found in English research article Introductions written by Indonesian authors in the field of Sciences}

Based on the data analysis from Biology, Physic and Chemistry articles, it is found that there are four types of authorial stance: these are hedges, boosters, attitudinal markers, and self-mention. Table 2 shows the percentage of authorial stance's types.

Table 3. Stance Types in RA Introductions in Sciences

\begin{tabular}{llccccr}
\hline No & Stance Types & Biology & Physic & Chemistry & Total & \multirow{2}{*}{ Percentage } \\
\cline { 3 - 6 } & & $\mathbf{n = 1 0}$ & $\mathbf{n = 1 0}$ & $\mathbf{n = 1 0}$ & $\mathbf{N = 3 0}$ & \\
\hline 1. & Hedges & 44 & 32 & 35 & 111 & 44.8 \\
\hline 2. & Boosters & 19 & 29 & 17 & 65 & 26.2 \\
\hline 3. & Attitudinal markers & 16 & 22 & 18 & 56 & 22.6 \\
\hline 4. & Self-mention & 6 & 9 & 1 & 16 & 6.5 \\
\hline & Total & $\mathbf{8 5}$ & $\mathbf{9 2}$ & $\mathbf{7 1}$ & $\mathbf{2 4 8}$ & $\mathbf{1 0 0}$ \\
\hline
\end{tabular}

Table 3 shows that the total frequency of authorial stance type from thirty RA introductions was 248. The frequency of authorial stance types in physic is 92 and this is greater than those in Biology with total number of 85 and in Chemistry was 71 . Hedge is the most frequent stance type employed by the Indonesian RA authors with the total number of 111 or $44.8 \%$. The examples are often, may, possible, can, usually, etc. The second most frequent stance type is boosters, with the total number of 65 or $26.2 \%$. The examples are especially, will, very, significant, etc. Then, the frequency of attitudinal markers is 56 or $22.6 \%$. The examples of attitudinal markers are easy, effective, important, main, problem, and many others. Finally, self-mention was found 16 times or $6.5 \%$. The examples are $I$, the researcher, the author, me, we etc.

\section{The devices found in each of authorial stance type of English research article Introductions written by Indonesian authors in the field of Sciences}

Each authorial stance type consists of different lexical categories that form attitudinal markers, booster, hedges and self-mention, such as adjective, adverb, noun, verb and modal. 
Miasari, Arsyad, Arono, EduLite: Journal of English Education, Literature, and Culture Vol.3, No.2, August 2018, 173-187 DOI: http://dx.doi.org/10.30659/e.3.2.173-187

\section{Hedges devices found in English research article Introductions in the field of Sciences}

The following tables present the total number of hedges found in thirty RA introductions.

\begin{tabular}{|c|c|c|c|c|c|c|}
\hline \multirow[t]{2}{*}{ No. } & \multirow[t]{2}{*}{ Hedges } & \multicolumn{3}{|c|}{ RA in the Field of Sciences } & \multirow[t]{2}{*}{ Total } & \multirow[t]{2}{*}{$\%$} \\
\hline & & Biology & Physic & Chemistry & & \\
\hline 1. & Verb & 3 & 1 & 2 & 6 & 5.4 \\
\hline 2. & Adjective & 1 & 1 & 4 & 6 & 5.4 \\
\hline 3. & Adverb & 12 & 7 & 9 & 28 & 25.2 \\
\hline 4. & Noun & 0 & 1 & 0 & 1 & 0.9 \\
\hline 5. & Modal & 28 & 22 & 20 & 70 & 63.1 \\
\hline & Total & 44 & 32 & 35 & 111 & 100 \\
\hline
\end{tabular}

Table 4 shows that there are five different lexical categories that manifest hedges. It can be seen that the most employed was modal and Biology RAs was the highest frequency with more than 25 modal verbs; Physic used more than 20 modal words and Chemistry about 20 modal verbs. The second most employed is adverb with 28 or $25.2 \%$ ( i.e., 12 adverbs in Biology, 9 in Chemistry, and 7 in Physic). Thirds are verb and adjective; they are 3 verbs in Biology, 2 in Chemistry and 1 in Physic. Besides, there was 1 adjective in Biology and Physic and 4 in Chemistry. The last was noun with the percentage of only $0.9 \%$. There was no noun in Biology and Chemistry but 1 in Physic. The following examples illustrate hedges employed by the Indonesian authors in their English RA introductions.

1. To overcome this problem, material substitution which may reduce the production cost of PSB must be investigated. (Bio-1)

2. The utilization of three types of LEDs that each emit a basic colour, i.e. blue, green and red, can produce secondary and tertiary colours, covering almost all colours in everyday life $[1,2]$. (Phy-2)

3. For the l-wave, the Dirac equations for central and non-central potentials are solved only approximately due to the contribution of the centrifugal term. (Phy-10)

4. The sol-gel process may be scaled up to synthesize $\mathrm{NiO}$ at a large scale at a relatively low cost. (Chem-2)

As can be seen from examples above, the use of "may" in example 1 is to show uncertainty about the information. While, the modal hedging "can" in example 2 is the most frequently used by the authors in Biology, Physic and Chemistry. Can is defined as an opinion of the authors toward a statement and to show probability expression. Beside that the second most commonly hedge devices is adverb, "approximately" in example 3 is one of the examples of adverb hedging, it can be used to avoid responsibility about the truth of the statement. Example 4 above shows that the authors used word "may" to express uncertainty about the truth of the statement. From these examples, it can be said that hedges can help authors to reduce the risk of contradiction. It can help enfeeble the authors' claim and to show uncertainty about the right of information taken by the authors. 


\section{Booster devices found in English research article Introductions in the field of Sciences}

There are five categories of Boosters that can be found in academic texts: they are verb, adverb, adjective, modal and noun. The following table shows boosters found in the corpus of this study.

Table 5. Booster in the English RA Introductions

\begin{tabular}{ccccccc}
\hline \multirow{2}{*}{ No. } & Booster & \multicolumn{2}{c}{ RA in the Field of Sciences } & \multirow{2}{*}{ Total } & \multirow{2}{*}{} \\
\cline { 3 - 6 } & & Biology & Physic & Chemistry & & \\
\hline 1. & Verb & 1 & 0 & 0 & 1 & 1.5 \\
\hline 2. & Adverb & 12 & 17 & 9 & 38 & 58.5 \\
\hline 3. & Adjective & 4 & 6 & 1 & 11 & 16.9 \\
\hline 4. & Modal & 2 & 6 & 7 & 15 & 23.1 \\
\hline 5. & Noun & 0 & 0 & 0 & 0 & 0 \\
\hline & Total & 19 & 29 & 17 & 65 & 100 \\
\hline
\end{tabular}

Table 5 shows that in Biology, Physics and Chemistry field, booster adverb is the most commonly used by the writers with $58.5 \%$, where the frequency in Biology was 12, in Physic was 17 and in Chemistry was 9. The results also show that the second boosting device was modal with more than $20 \%$ from total frequency. Chemistry RAs have the highest frequency with 7,6 in Physic and 2 in Biology. The third is an adjective with the percentage of 16.9 from total frequency. There are 6 adjectives in Physic, 4 in Biology and 1 in Chemistry RAs. The fourth is verb. Verb did not much occur in this research, there was 1 verb in Biology while there is verb in Physic and Chemistry. Finally, noun as a booster was not found in the RAs. Here are the examples of boosters in each field of sciences.

1. This more accurate dual approach using anatomy established the status of the putative natural hybrid of Anaphalis discovered by the authors. (Bio-4)

2. Multidrug resistant bacteria are a serious health problem these days. (Bio9)

3. However, research on a quantum dot system using DFT is not fully explored yet. (Phy-8)

4. At low temperatures, the poly-condensation process takes place very slowly, especially propagation, which consists of olation and oxolation that allow controlling the formation of pores, the crystal structure and morphology [25]. (Chem-5)

From example 1 above shows adjective booster, an adjective "accurate" was used to express the authors' stance about anatomy approach. While, adjective "serious" in example 2 was used to show the certainty expression about the multidrug resistant backteria statement. The stance adverb "fully" in example 3 expressed the author's assurance about Quantum dot system using DFT. Adverb stance "very" in example 4 was to express the authors' judgement toward poly condensation. From the examples above showed that the use of booster adverb can be form of adjective, adverb, noun, verb and modal. It can be used to express the authors' certainty or to emphasize a point that they believed. 
Miasari, Arsyad, Arono, EduLite: Journal of English Education, Literature, and Culture Vol.3, No.2, August 2018, 173-187 DOI: http://dx.doi.org/10.30659/e.3.2.173-187

\section{Attitudinal markers devices found in English research article Introductions in the field of Sciences}

The following table shows the attitudinal devices in each field (Biology, Physics, and Chemistry).

Table 6. Attitudinal Markers in the RA Introductions

\begin{tabular}{ccccccc}
\hline No. & $\begin{array}{c}\text { Attitudinal } \\
\text { marker }\end{array}$ & \multicolumn{2}{c}{ RA in the Field of Sciences } & Total & \% \\
\cline { 3 - 6 } & Biology & Physic & Chemistry & & \\
\hline 1. & Adjective & 12 & 15 & 16 & 43 & 76.8 \\
\hline 2. & Adverb & 2 & 5 & 1 & 8 & 14.3 \\
\hline 3. & Noun & 1 & 2 & 0 & 3 & 5.4 \\
\hline 4. & Verb & 1 & 0 & 1 & 2 & 3.6 \\
\hline & Total & 16 & 22 & 18 & 56 & 100 \\
\hline
\end{tabular}

Table 6 shows there are four different attitudinal markers found in the RA introductions in the corpus of this study: they are adjective, adverb, noun and verb. RAs in Physics have the highest frequency of attitudinal markers with 22 while RAs in Chemistry and Biology have 18 and 16 respectively. As seen in Table 5, adjective is the most common manifestations of attitudinal markers with the percentage of $76.8 \%$. From the total frequency, RAs in Chemistry uses more adjectives than RAs in Biology and Physic. The second was adverb with percentage about $14.3 \%$. Physic had more adverb than Biology and Chemistry, it was about 5. While, the frequency of adverb in Biology was 2 and Chemistry was only 1 . The third device was noun with $5.4 \%$. The total frequency of noun was 3. Noun in Physic were 2, in Biology was only 1. But, noun in Chemistry was not found in this research. The last device is verb with total number of 2 or $3.6 \%$. Verb and Noun is less frequently found in the RA introductions. The following examples illustrate the usage of attitudinal markers found in the RA introductions in the corpus of this study:

1. Fast growth and rapid turnover of fine roots become important factors in nutrient cycles including $\mathrm{N}$ cycle. (Bio-3)

2. These problems must be resolved to suppress the amount of carbon dioxide that released into the atmosphere, (Chem-10)

3. Nano particles have unique properties, such as high electrical conductivity, toughness, ductility and formability of ceramics. (Chem-2)

From example 1 above, it can be seen that the authors used an adjective "important" to stress of the judgement and it is to state the importance of the field that they are researching. In sentence 2, the word "problems" used by the authors to show negative view about the effect of global warming; whale adjective "unique" in example 3 shows different from usual information in the research. Thus, it can be seen that the use of attitudinal markers in form of adjective, adverb, noun and verb is to show the importance of the information in order to build the field that they are researching, beside that it can be used to help the writer to express their feeling toward the information that they are presenting such as stressing the information that they are thinking as important information in their research and supported information. 


\section{Self-mention found in English research article Introductions in the field of Sciences}

This is the detail result of analysis about self-mention used by the authors in writing English research article Introduction in Biology, Physic, and Chemistry.

Table 7. Self-mention in the RA Introductions

\begin{tabular}{llccccc}
\hline \multirow{2}{*}{ No } & Self-mention & \multicolumn{2}{c}{ RA in the Field of Sciences } & \multirow{2}{*}{ Total } & \multirow{2}{*}{$\%$} \\
\cline { 3 - 6 } & & Biology & Physic & Chemistry & & \\
\hline 1. & Subjective pronoun & 5 & 8 & 1 & 14 & 87.5 \\
\hline 2. & Objective pronoun & 0 & 0 & 0 & 0 & 0 \\
\hline 3. & Common nouns & 1 & 0 & 0 & 1 & 6.25 \\
\hline 4. & Possessive adjectives & 0 & 1 & 0 & 1 & 6.25 \\
\hline & Total & 6 & 9 & 1 & 16 & 100 \\
\hline
\end{tabular}

It can be seen in Table 7 that the total number of self-mention in Physic was 9. It is higher than Biology and Chemistry with total frequency 6 in Biology and 1 in Physic. Subjective pronoun was the higher percentage, it was about $87.5 \%$. Common noun and Possessive adjectives were the second higher percentage with $6.25 \%$. Objectives pronoun was not found in this research. It is found that subjective pronoun "we" is the commonly used by the authors, most of the data found that the authors prefer to use "we" in presenting their self in the research. The researcher only found 1 possessive adjective "our" and 1 common noun "the authors" in thirty research article introductions. The authors in Chemistry is the least frequent in mentioning their self in their texts compared to authors in other science fields such as Physic and Biology. Below is an example.

In this paper, we describe the development of a novel ternary $\mathrm{CoFe} 2 \mathrm{O} 4 / \mathrm{CuO} / \mathrm{CoFe} 2 \mathrm{O} 4$ as a GMR material for magnetic sensor application. (Phy-1)

The word "we" in this example was used to present the authors' identity as performer in that research. It can be concluded that from thirty articles show that the authors were relatively low in mentioning their self as the researcher. Besides, they were no variation of self-mention from thirty articles.

\section{Results}

The first research question in this study is how Indonesian authors use authorial stances in their English RA introductions the field of sciences. The finding show that there are two stances appeared in data: they were neutral and positive stances but no critical stance found in this research. In neutral stance the authors only state the information and do not show their attitude toward the cited information (Pho, 2013). While the positive stance can be used to help the authors in emphasizing the information that can support and strengthen the importance of their research (Getkham, 2016). According to Adnan (2016), the critical stance is rarely used by Indonesian authors because Indonesian authors do not have enough confidence to criticize the information. 
Adnan (2016) suggests that there are two reasons of lack of critical stance: practical and cultural reason. The practical reason is the lack of resources available and the lack of time the authors have and cultural reason is that authors usually get information aurally such as from seminar rather than reading many books or supported information.

The second research question concerns authorial stance types used by Indonesian authors in RA introductions in sciences. Among the four types of authorial stance proposed by Hyland (2005), it is found that all types appeared in Biology, Physic and Chemistry, such as hedges, booster, attitudinal markers and self-mention. The most dominantly used by the authors was hedges, followed by booster, then attitudinal markers and the last was selfmention. Hedges can help authors make the strategy in order to reduce the force of their statements (Dontcheva and Navratilova, 2016). Additionally, Hyland (1998) says that the use of hedges in writing can present a weakening through the writers claim, show the information that is presented as opinion, it also can be convey to deference, humility and respect to a view. It means that it will show the authors' attitude to the audience. Form the result of the analysis, there are some words that used by the authors in writing Introduction, such as may, frequently, can, approximately, assume, could, usually, likely, probably, commonly, etc. The finding of this study is in line with that of Getkham (2016) who also found four types of authorial stance in Thai students' doctoral dissertation and hedges is the most frequently used in the Introduction and Discussion sections of the dissertations. Besides, Serholt (2012) in his research also showed that hedges appeared more frequently in Introduction and Discussion sections than in other sections of RAs. According to Farrokhi and Emami (2008), authors utilize hedges as the politeness strategies which can soften force of utterance such as accusation, critics or disagreement, thus those hedges can be used to express the author's view tentatively or unconfidently. Thus, the use of hedges is able to soften the texts; it is because in introduction section authors must write arguments that will determine the readers' impression.

Booster is also used in introduction section as a tool to emphasize what the writer's believe. As suggested by Hyland cited in Dontceva and Navratilova (2016), the use of boosters helps them close down alternatives and to show a high degree of certainty". Similarly, Serholt (2012) found that booster used by academic authors to convey their interpretation as self-evident or as a generally accepted idea or fact. It indicates that the authors used booster to show evidence as accepted idea or fact, and it would show the authors' confidence and believe toward a statement.

Attitudinal markers and self-mention are also used by the authors in the corpus of this study. These words indicate that the authors give a signal to readers that the information is important and unusual. The researcher found that the authors much used same word such as adjective "important" as the commonly attitudinal marker appear in introduction section. This finding is in line with that of Agcam (2015) who found that both native and non-native authors tend to use more or less the same linguistic forms to express their attitudes when they write academically. Similarly, Blagojevic (2009) found that Serbian writers has a greater tendency towards using attitude markers in their texts in comparison to English academic writers; it is probably because a 
variety of cultural, social, and psychological factors in the two writing cultures.

Self-mention such as we, the author and our self-mention are also found in the data of this study although very infrequently. Getkham (2016) also found self-mention in his study with a relatively low frequency. Self-mention is employed to present authors as an informed (Getkham, 2016). It can be said that self-mention used by the authors is to inform readers the contribution of the author's research findings in their RAs.

The last research question is the linguistic devices found in each of authorial stance type in English RA Introductions written by Indonesian authors in sciences. In each type of authorial stances, it is found that there are some devices that manifest hedges, booster, attitudinal markers, and selfmention. The devices were adjectives, adverbs, verbs, modals and nouns, for self-mentions were first person pronouns (subjective pronoun), common nouns, and possessive adjectives. The highest amount of devices in hedges was the using of modal. While in booster was adverb. In attitudinal markers was an adjective. The last, in self-mention was subjective pronoun. However, in self-mention type, the devices are less found by the researcher in introduction section. The finding is along with the finding of Getkham (2016) who found that the writers used more self-mention in discussion section rather than in introduction section, and he explains that "In the Introduction, the writers in this study may be reluctant about the value of their research whereas in the discussion, they may be more confident as they see the valuable findings of their research". It means that the authors feel more confidence in discussion rather than in introduction because they are supported by real evidence.

The possible reason why Indonesian authors in the corpus of this research do not prefer using self-mention is because they believe that without stating self-reference readers know their objective. This finding is different from that of Karahan (2013) who found that writers often used self-mention in their RAs in order to show the originality of their research. However, Cakir (2016) suggests that authors in natural sciences such as Biology, Physic and Chemistry often reveal objectivity; thus there should be an impersonalized voice in hard sciences. Directorate of National Education Personnel (2008) also says that scientific journal as a means of communication and will be accepted by the scientific community if the result accountable empirically and objectively. It means that in those three articles the authors tend to be objective as the way to express their feeling.

Another research about authorial stance was conducted by Cakir (2016) when he compared stance adverbs found in English RA abstracts written by Turkish and native English speakers. According to Cakir, the Turkish writers used less stance adverbs than English native writers. In other words, native writers used more stance adverbs than non-native writers. Duenas (cited in Getkham, 2016) also claims that native English speaker use of self-mentions was more frequent than non-native speakers. The finding of this research also showed that the use of the words which indicate stance is still less than previous study, in other word the previous study has more variation than the finding of this research. According to Adnan (2016) Indonesian authors' attitude to the cited information is mostly positive and neutral; it is because 
three related factors, such as lack of resources and lack of time, and young and developing academic culture. So, it can be the possible reason that makes the authors used same words to express their attitude in their writing.

Mentioning stance when the authors citing information is important, whether neutral, positive and critical stance. Beside that the more use the variation of the stance in writing, the more the author can use references, and it is something that is expected to be used, because these are as an indicator of good or bad quality of an article. Hopefully, this research can provide insight for the author in the scope of EAP/ESP.

\section{CONCLUSION}

From three authorial stances suggested by Adnan, there are two stances found in this research (i.e. neutral and positive), but there was no critical stance. From the four types of authorial stance proposed by Hyland, (Hedges, Booster, Attitudinal Markers, and self-mention) all of them are found in this research. For the devices in each types of authorial stance, there were noun, verb, adverb, adjective and modal while self-mention words are only we, the author and our. The differences of authorial stances among the three groups of RAs are not found significant in term of frequency. The different frequencies are probably because the different number of words or the length of the introduction.

From the results of this study, it is suggested that Indonesian authors should consider using all authorial stances (i.e. positive, neutral and critical) when citing information in order to help them in arranging convincing arguments in writing introduction. Besides, the authors can use more devices of stance types in form of adjective, adverb, noun, verb and modal, in order to arrange a good argument and reveal their claim in Introduction section by using variation words. Additionally, for further research, researchers can focus on Social science and Humanities RAs in analysing the authorial stance, or compare between RAs in national and international journals of the same or different sections of articles.

\section{REFERENCES}

Adnan, Zifirdaus. (2016). Citing behaviours in Indonesian humanities research articles, Australia: University of New England.

Ağçam, R. (2015). A corpus-based study on attitudinal stance in native and non-native academic writing. International Journal of Humanities Social Sciences and Education (IJHSSE), 123-129.

Arsyad, Safnil. (2000). Rhetorical structure analysis of the Indonesian research articles. unpublished dissertation. Canberra: Australian National University.

Arsyad, Safnil. (2016). Writing international journal articles using English rhetorical style. Jakarta: Halaman Moeka Publishing.

Blagojevic, Savka. (2009). Expressing attitudes in academic research articles written by English and Serbian authors. Facta Universitas Series: Linguistics and Literature Vol. 7, No 1, 2009, Pp. 63 - 73 
Çakır, H. (2016). Native and non-native writers' use of stance adverbs in english research article abstracts. Open Journal of Modern Linguistics, 85-96.

Chang, P. (2010). Taking an effective authorial stance in academic writing: Inductive learning for second language writers using a stance corpus. USA: University of Michigan.

Directorate of National Education and Personnel. (2008). Penulisan karya ilmiah. Jakarta: Departemen Pendidikan Nasional.

Directorate of Higher Education of Ministry Education and Culture. (2012). Publikasi karya ilmiah. Retrieved January 20, 2017, from www.kopertis 12.or.id/2012/.../surat-dirjen-dikti-no-152et2012-tent.

Dontcheva, \& Navratilova. (2016). Cross-cultural variation in the use of hedges and boosters in academic discourse. Prague Journal of English Studies, 163-184.

Dzung Pho. (2013). Authorial stance in research articles. Vietnam: National University.

Farrokhi, F., \& Emami, S. (2008). Hedges and boosters in academic writing: native vs. non-native research articles in applied linguistics and engineering. The Journal of Applied Linguistics Vol. 1, No. 2 , 63-97.

Getkham, K. (2016). Authorial stance in Thai students' doctoral dissertation. English Language Teaching; Vol. 9, No. 3, 80-95.

Hasan, A. I. (2009).Penulisan karya ilmiah bagi mahasiswa. Retrieved January 25 , 2017, from http:/ /imronmangkang.blogspot.co.id/2013/10/penulisan-karya ilmiah-bagi- mahasiswa.html

Hyland. (1998). Boosters, hedges and the negotiation of academic knowledge. Retrieved July 5, 2017, from http://www2.caes.hku.hk/kenhyland /files / 2012/08/Boosting- hedging-and-the-negotiation-of-academic knowledge.pdf

Hyland, K. (2005). Stance and engagement: a model of interaction in academic discourse. London: University of London.

Karahan, P.(2013). Self-mention in scientific articles written by Turkish and non-Turkish authors. Procedia - Social and Behavioral Sciences, 305322.

Mc'Hugh, M. (2012). Inter-rater reliability: kappa statistic. Retrieved July 5, 2017, from https://www.ncbi.nlm.nih.gov/pmc/articles/PMC3900052/

Serholt, Sofia. (2012). Hedges and boosters in academic writing. Retrived on July 25, 2017, from pareonline.net

Soule, D. P., Whiteley, L., \& McIntosh, S. (2007). Writing for scholarly journals. Glasgow: University of Glasgow.

Stemler, S. (2001). Practical assessment research and evaluation. Retrieved July 5, 2017, from pareonline.net/getvn.asp?v=7\&n=17

Supriyadi. (2013). Menulis karya ilmiah dengan pendekatan konstruktivisme. Gorontalo: UNG Press Gorontalo.

Warsono. (2016). Language Transfer in Language Learning, Edulite: Journal of English Education, Literature, and Culture, Vol. 1, No. 1, pp: 103-113. 